\title{
INICIO Y ROLES EN UN QUEHACER PEDAGÓGICO: EL MAESTRO DE LAS ESCUELAS NORMALES DE CALDAS 1963-19781
}

* Docente Universidad de Caldas, Departamento de Historia y Geografía, Magíster en Educación con énfasis en Didáctica de las Ciencias Sociales, Universidad de Caldas.

**Docente titular Universidad de Caldas. Ph. D. en Ciencias de la EduD. en Ciencias de la Edu cación RudecolombiaUPTC Tunja, posdoctorado en Narrativa y Ciencia Universidad Santo Tomás. E-mail: yasaldez@ ucaldas.edu.co
${ }^{1}$ El presente artículo se basa en los resultados de la investigación titulada: El maestro de las escuelas normales superiores de Caldas 1963 - 1978. Grupo Maestros y Contextos, Universidad de Caldas. Elementos relacionados a este trabajo se presentaron en XV Congre taron en el $x v$ congres Colombiano de Histori en la ciudad de Bogotá octubre de 2015.

\author{
BEGINNER AND ROLES OF THE TEACHING DAILY EXPERIENCE: \\ THE TEACHER OF ESCUELAS NORMALES OF CALDAS BETWEEN \\ 1963-1978
}

\author{
Por: Paula Tatiana Pantoja Suárez* \\ Yasaldez Eder Loaiza Zuluaga**
}

Recibido: 11 de febrero de 2016 - Aprobado: 9 de junio de 2016

\section{RESUMEN}

El presente artículo tiene como propósito comprender algunas de las razones por las cuales los maestros de las escuelas Normales de Caldas, decidieron iniciarse en este oficio. Es un estudio de corte histórico que se ubica entre los años 1963 y 1978, período en el que se presentaron importantes reformas a estas instituciones, que afectaron el quehacer pedagógico y las acciones educativas asumidas por los maestros; así como la forma de adaptarse a las propuestas de transformación y legislación cimentadas desde las directrices educativas impuestas como resultado de un acomodamiento a las políticas de vinculación a este oficio; así mismo, se reconoce que el desempeño en este oficio, estuvo marcado por una época de manifestaciones culturales, sociales, económicas e intelectuales, al igual que presiones propias del ejercicio docente.

Palabras claves: Pedagogía, Maestro, Magisterio, Escuelas Normales, Roles, Legislación Educativa y Reformas.

\begin{abstract}
This paper aims to understand some of the reasons why teachers of the Normal schools of Caldas, decided to take this job. It is a historical study located between 1963 and 1978, a period in which significant reforms to these institutions affected the pedagogical practice and educational activities undertaken by teachers; as well as the way to adapt to the transformation and legislation proposals established from the education guidelines imposed as a result of the policies of hiring teachers. Likewise, it is recognized that performance in this job, was marked by a time of cultural, social, economic and intellectual manifestations, as well as the inherent pressures of the teaching practice.
\end{abstract}

Key words: Pedagogy, Teacher, Teaching, Normal Schools, Functions, Educational Legislation 


\section{Introducción}

l presente escrito es resultado de una investigación históricoeducativa, que da cuenta de las condiciones e intereses que llevaron a los maestros a iniciarse en este oficio dentro de las Escuelas Normales del Departamento de Caldas, permitiendo además identificar los procesos de organización de estas instituciones y la situación vivida por los maestros entre los años 1963 y 1978, período en el cual se presentaron dos reformas de gran importancia y trascendencia para estas instituciones como fue el Decreto 1955 de 1955, con el que se estableció una nueva reorganización a la educación normalista además el decreto 1419 de 1978, que obliga el cambio de nombre de las Escuelas Normales por el de Institutos de Bachillerato Pedagógico, lo cual implicó afectaciones tanto en rol del maestro, como en las mismas instituciones.

Este es un estudio que se enmarca dentro del campo de la Historia Social, pues el objeto primordial de la investigación es comprender en la comunidad de maestros de las Escuelas Normales del departamento de Caldas, las historias sobre sus inicios, roles y desempeños, los cuales reflejan las condiciones y presiones propias del ejercicio docente; así como la presencia del pensamiento educativo-pedagógico en la construcción de una identidad de los maestros y su compromiso social.

Los objetivos de la investigación desarrollados en el artículo son: construir una caracterización del maestro de las Escuelas Normales Superiores de Caldas, contrastar los elementos nacionales de tendencias y leyes educativas con las lógicas reales del ingreso, formación y prácticas docentes de los maestros que se formaron entre 1963 y 1978, todo ello con el fin de aportar a la construcción de una historia de la formación de educadores colombianos, particularmente en un departamento y una región del país donde más allá de la norma existieron estructuras sociales vitales sobre el papel y la labor del educador como sujeto social y político.

\section{3-1978: Tensiones entre las tendencias pedagógicas de la tecnología y conservar estructuras}

l l período entre 1963 y 1978 se destacó a nivel nacional e internacional 1 por el surgimiento de movimientos políticos de izquierda y el 1 pacto bipartidista conocido como Frente Nacional. Sin embargo, para el caso particular del departamento de Caldas, sus leyes y prácticas educativas, los maestros normalistas no reconocieron una influencia muy 
${ }^{2}$ El modelo educativo de la Tecnología Instruccional o Educativa fue desarrollado a plenitud en la década de 1970 El magisterio, asumió la concepción del currículo enmarcado en el modelo. sustituyendo la estructura clásica por la planeación, por la planeación, los objetivos y la evaluación formuladas en las unidades curriculares y determinadas por las técnicas educativas.

${ }^{3}$ Angulo, A. (2007). Conceptos pedagógicos alemanes en la gicos alemanes en la La Segunda Guerra Mundial y la actualidad. Revista Matices. Bogotá: Universidad Nacional de Colom Nacional de Colom bia. En: hitp://WwW. bdigital.unal.edu co/15945/6/10683 22337-1-PB.pdf marcada de estos movimientos en su desempeño y ejercicio docente, pues su preocupación principal era mantener su trabajo, su imagen ejemplarizante y de permanente respeto al gobierno, así no estuvieran de acuerdo con sus políticas $\mathrm{y}$, fundamentalmente un respeto y fortalecimiento de las normas y valores religiosos.

La llegada de tendencias como la Tecnología Educativa ${ }^{2}$ tuvo un impacto en el uso del material de divulgación diseñado por la tercera Misión Alemana, que permitó reconocer desde los discursos de los maestros y sus planeaciones, e incluso en la "facilidad" que muchos visualizaron de ejercer la docencia a partir de seguir completamente el material diseñado a través del objetivo alemán de tecnificar la educación colombiana; desde la perspectiva de Angulo, el objetivo

(..) principal fue tecnificar la educación de la enseñanza básica primaria, dotar las instituciones y capacitar al personal docente. Esta misión realizó una evaluación de las funciones y desarrollos de la primaria en la educación colombiana, y con los resultados arrojados en 1967 se puso en la tarea de reorientar las normas y las acciones vigentes para lograr mayor efectividad. El más importante logro de esta misión fue la dotación de material didáctico en las escuelas primarias y el trabajo con el personal docente rural y urbano, dado el factor de crecimiento de la población. $(2007: 15)^{3}$

Estos elementos de renovación de educativa no trasformaron el legado tradicional sobre la labor del docente, pues en realidad más allá del material diseñado para la enseñanza primaria, dentro de los espacios cotidianos seguía primando una acción pedagógica enmarcada en una pedagogía tradicional, con una gran influencia del pensamiento católico. Es en esta lógica de contradicciones que los maestros normalistas de Caldas afrontaron y experimentaron el influjo de los movimientos sociales, culturales y las alianzas políticas que marcaron este período.

En el marco legal de la educación colombiana, las décadas de 1960 y 1970 implicaron un proceso de continuo ordenamiento de la educación, desde las políticas trazadas por la Oficina de Planeación de Educación Nacional con la formulación del Primer Plan Quinquenal, del cual se desprende en 1963 el Decreto 1955. La reforma prescrita en dicho Decreto, presentó un fuerte componente psicológico en la formación del maestro y buscó vincular la 
educación con políticas educativas foráneas desplegadas en la época. Ante esta reforma y la planteada en el Decreto 1710 del mismo año, se da la introducción en la educación colombiana de la Tecnología Instruccional, la cual se mostró fuertemente en las Escuelas Normales a partir de la elaboración de las guías de instrucción que se elaboraron con la presencia de la Tercera Misión Alemana y que se difundieron en todo el país especialmente a mediados de la década de 1970.

Ahora bien, al finalizar la década de 1970, con la expedición del decreto 1419, de 1978," se da un proceso que afecta tanto el rol del maestro, como el de las mismas instituciones, al obligar el cambio de nombre de las Escuelas Normales por el de Institutos de Bachillerato Pedagógico; por lo tanto, en estas instituciones se dejó de otorgar el título de Maestro. A pesar de la denominación, en términos sociales se han considerado a las escuelas normales como las que se dedican a la formación de los maestros.

Este último elemento fue lo que motivó en parte el desarrollo de esta investigación, en tanto pretendía reconocer en qué medida se cumplen estos postulados y principios pedagógicos y cuál era el rol de los maestros al respecto; en tal sentido la pregunta orientadora de la investigación es: ¿Cuáles fueron las razones que motivaron a los maestros a elegir esta profesión y qué tipo de pensamiento pedagógico identificaba su quehacer? De tal suerte que, al comprender esta situación, se podría dar cuenta de la forma como se orientó la educación en el período de estudio, por parte de los maestros procedentes de las Escuelas Normales de Caldas.

\section{Algunas consideraciones sobre el maestro normalista}

7 l considerar la variedad histórica de las imágenes del maestro desde el punto de vista de un planteamiento pedagógico triplemente 1 desplegado, se puede remontar a tres grandes modelos que, a su vez, corresponden a tres antropologías claramente diferenciables. Según Pestalozzi, el hombre puede ser considerado como obra de la naturaleza, como obra de la sociedad o como obra de sí mismo, y de manera correspondiente al maestro se define, respectivamente, como auxiliar de la naturaleza, como agente de la sociedad o como representante de una humanidad realizada, es decir, como persona (Parnett, 1986:50) ${ }^{5}$.

Al abordar el tema sobre la formación de maestros, es innegable la necesidad de hablar de las escuelas normales, creadas con esta intención, especialmente
${ }^{4}$ En 1978 con la expedición del Decreto 1419 se establece el cambio oficial de las Escuelas Normales, en cuanto a surción de formar maestros, por el de Bachilleratos Pedagógicos con lo que el Estado colombiano dejó de otorgar el título de Maestro; estableció los marcos legales para el diseño $y$ la administracion no y la administracio curricular y. presentó a la comunidad como un agente educativo fundamental, como un agente participante del currículo.

${ }^{5}$ Parnett, J. (1986). La imagen del maestro en la historia. En: Revista educación y cultura, Número 8, Bogotá. 
${ }^{6}$ De allí que muchos de los que se dedicaban a esos menesteres lo hacían únicamente por buen voluntad por buena voluntad, personales, sin atender a la formación pedagógica, que en todos caso faltaba; sin embargo, es necesario reconoce que muchos de esos maestros, a quienes $s$

haestros, a quienes se cu llaró empiricos, cumplieron su labor, por demás admirable llenaron una necesidad y colmaron los vacíos existentes por la falta de maestros formados. RESTREPO, Bernardo.

Formacín, yermapatación del magisterio. Bogotá: Biblioteca de Educador. Librería Voluntad, 1970. P. 10

${ }^{7}$ Loaiza, Y. (2015). Origen de las Escuelas Normales en el DeNormales en el Departamento de Caldas. Revista Historia de la Educación Latinoamericana Vol. 18 No. 26 enero - junio 2016 ISSN: 0122-7238 - pp. 47 - 70 . En: http: revistas uptcedu revistas/index.php historia educacion latinamerican/article/ view/4365/3772

${ }^{8}$ Aportes del profesor José María Rodríguez, en su libro El manual de pedagogía de los años sesenta, con el cual se formaron buena parte de los normalistas de Colombia y especialmente de los Departamentos de Antioquia y Caldas en los años sesenta $y$ setent Rodríguez, José María. Manual de pedagogía de los años sesentas. Medellín: Bedout, 1961. P. 156

${ }^{9}$ En la historia de Colombia la iglesia católica ha tenido innumerables acontecimientos que desde la época de la conquista le dieron puesto destacado y prestigio, lo que les permitió durante muchos años tener de la educación en nuestro país. Ver: Parra Báez, Lina Adriana, 174. Es importante anotar que desde que se firmó el plebiscito en 1957, la religión católica confirmó el Concorda-

to de 1887 , que echab atrás lo mediatizado en la reforma liberal de 1936. A la dominación del sable y los partido se sumó oficialmente la dominación de la sotana. El gobierno conservador de Pastrana Borre-

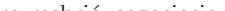
nuevo acuerdo y el libenuevo acuerdo y el libe-
ral López Michelsen lo para los primeros niveles de enseñanza. En Colombia, dichas instituciones vienen funcionando con esta finalidad desde el siglo XIX. Aunque en un comienzo no tuvieron mucho auge y por lo tanto, los maestros que allí se formaban, no alcanzaban a llenar las necesidades del país; por ello se acudía a los individuos que "por amor al arte", ${ }^{6}$ quisieran trabajar en educación; sin embargo se debe reconocer que siempre, independiente de las razones por las cuales se escogiera este oficio, se dieron orientaciones y condiciones para ejercerlo. Ante estos elementos Loaiza plantea:

En el departamento de Caldas el surgimiento y creación de las Escuelas Normales data de 1909 cuando se funda la Escuela Normal de Varones de Manizales y 1910 cuando se aprueba la fundación de la Escuela Normal de Señoritas de Caldas. Posterior a ello y luego de casi cuatro décadas se inicia un proceso interesante de creación de otras Escuelas Normales en el departamento con el concurso y empeño decidido de algunas comunidades religiosas que existían en algunos municipios del departamento. $(2015: 50)^{7}$

Para el caso de Colombia y especialmente para el departamento de Caldas, las instituciones encargadas de la formación de sus futuros maestros, se supeditaron a diversos planteamientos, entre ellos se destacó la publicación del maestro José María Rodríguez, "Manual de pedagogía", 8 en la cual planteaba, con base en los requerimientos y programas del Ministerio de Educación Nacional; que el objeto primordial de la pedagogía era el niño, y el agente de la educación el maestro, proponiendo para este último un perfil específico compuesto por tres campos que garantizaría, en alguna medida, elevar y dignificar la profesión magisterial: Cualidades morales: Ética profesional, firmeza de carácter, dignidad, prudencia, benevolencia, dulzura; Cualidades físicas: Buen funcionamiento de sus órganos visual y auditivo, elocución adecuada, buen porte exterior y Cualidades pedagógicas: Vocación magisterial, esto es, apostolicidad: Es fácil conocer la vocación de un maestro; llega temprano, sale de último, sus mejores amigos son los niños, trabaja con devoción en las aulas, estudia de continuo para provocar el mejoramiento de los discípulos. Los aportes extractados del texto del profesor Rodríguez Rojas, permiten identificar la marcada injerencia de las comunidades católicas en la formación escolar y muy especialmente en las escuelas normales, no debe olvidarse que en su gran mayoría, estas instituciones eran dirigidas por comunidades religiosas. ${ }^{9}$ 
De otra parte, es necesario resaltar que, con respecto a la imagen y al rol del maestro, ${ }^{10}$ Agustín Nieto Caballero planteaba que el maestro debía poseer las cualidades acordes con su nombre: "Rectitud en la vida, discreción, tacto, entusiasmo y optimismo; pero sobre todo, tiene que representar al mismo tiempo que una fuerza espiritual una fuerza moral. La mejor lección que puede dar es su propia conducta. La bondad, el decoro, la sencillez, la hombría de bien, de enseñar con el ejemplo, nunca con palabras solamente". (Nieto Caballero en Gantiva, 1985 , p. 40) $)^{11}$

Pensar entonces, en la imagen y función de los maestros lleva a reflexionar cómo se hace, por qué escoge esta profesión; es decir, las expectativas que lo llevaron a matricularse en la modalidad pedagógica; al respecto, investigaciones como la realizada por Tezanos (1982, pp. 2-3) ${ }^{12}$, dan cuenta de algunas de las condiciones por las cuales se toma la decisión de formarse como maestros, "Yo elegí la formación pedagógica por varias circunstancias, por que lo capacita a uno más para la vida cotidiana, por que ... además a mí me nace ser maestro, yo siempre desde pequeñito quise ser maestro, me gusta enseñar, me gusta impartir conocimientos y puesto que los recursos económicos de mi hogar no eran suficientes para acudir a la Universidad, entonces, en el magisterio al menos tiene uno la posibilidad de desempeñarse y a la vez ayudar a los demás hermanos que quieran capacitarse más"

Manifiesta también Tezanos (En Parra Sandoval, 1986, p. 39) ${ }^{13}$, que se evidencian tres tendencias de la visión que tienen los maestros de su profesión y de sus estudios en una Escuela Normal. El primer caso hace referencia por una parte a la concepción de la profesión docente como una vocación innata, y por otra la posibilidad que brinda de vincularse prontamente al mercado de trabajo, factor que está determinado por el origen social del maestro. El segundo entrevistado entiende la docencia como una solución transitoria para poder tener acceso a otra profesión que considera de mayor prestigio social y la tercera respuesta expresa claramente la imagen tradicional de "apóstol", el que no espera nada de su profesión y quiere entregarse todo.

Es entendible la visión de apostolado que enmarcó el ejercicio de muchos docentes, pues un aspecto que imprimió la formación de muchos maestros, especialmente los caldenses, fue el hecho de haber sido formados, en su mayoría, por comunidades religiosas, ${ }^{14}$ por curas y monjas, que se encargaron de difundir dogmas, principios religiosos, doctrinas y experiencias morales, con una cultura encuadrada en la cristiandad, que en parte, particularizó y culminaría; el Estado colombiano adquiere así su propio carácter confesional. Sánchez, R.pp. 80-81. El nuevo Concordato firmado en 1973, expresó la posibilidad de que en los territorios de misión, la iglesia $\mathrm{CO}-$ laborara con el sector educativo oficial mediante contratos ajustados a criterios acordados en común acuerdo entre el Gobierno Nacional y el Consejo Episcopal. Medidas que reflejan el gran interés de la iglesia por atenuar la injerencia y autonomía en lo que respecta a la educación en estos territorios. Ver: GONZALEZ, F. pp. 131-132.

${ }^{10}$ Sobre el rol del maestro véase: BURDíN, Joel. El mundo cambiante y sus implicaciones para la educación de los maestros: COGAN Morris. Problemas actuales de la educación de profesores. Seminario sobre formación de docentes para el sistema educativo. Bogotá octubre de 1975. BUSTAMANTE, $\mathrm{Ce}-$ cilia y ROZO Jaime Evaluación de plan empleado en el instituto pedagógico para la formación de maestros de la escuela primaria. Bogotá 1976 (Tesis). ICOLPE. El personal docente $Y$ otros profesionales de la educación. Bogotá, 1975. RODRÍGUEZ Simón. Op. Cit. GAVIRIA, Nicolás. Op.Cit.; PARRA SANDOVAL, Rodrigo La escuela inconclusa. Plaza y Janés Editores, Bogotá, 1986 . y DUQUE, Ignacio. Problemática Educativa Colombiana, Bogotá: Biblioteca del Educador Editorial Voluntad, 1972.

${ }^{11}$ Gantiva, J. (1985). Agustín Nieto Caballero y la Escuela Nueva. En: Revista Educación y Cultura, No 3 , marzo, Bogotá

${ }^{12}$ Parra, R. y otros (1982). La profesión del maestro y el desarrollo en Colombia. Ensayo publicado en: Revista Proyecciones Educativas, MEN, Bogotá.

${ }^{13}$ Parra, R. (1986). La escuela inconclusa. Plaza y Janés Editores, Bogotá. 
${ }^{14}$ Cabe anotar que, según la religión católica la iglesia fue el primer maestro, el primer pedagogo, la máxima autoridad pedagógica donde el maestro era quien emitía discursos, quien tenía experiencias el que sabía educar mediante la invitacion a que cada uno construyera su propia experiencia. Tal vez esa fue la razón por la cual las comunidades religiosas como los Jesuitas Franciscanos, Dominicos, Marianos, Claasumieron como su responsabilidad con la sociedad, la educación de los menos favorecidos para quienes les era difícil el acceso a ést por motivos económicos, de distancia, sociales, entre otros.

${ }^{15}$ Quiceno, H. (1998) Breve recorrido histórico sobre el saber pedagógico. En: Revista Edu cación y Pedagogía No 19 Y 20. Medellin 20. Medellin: Universidad de Antioquia.

${ }^{16}$ Acevedo, J. (1978). Educación y contratación. Contribución al análisis del problema de la contratación en la educación. Universidad de Antioquia, Facultad de Educación. Medellín: Azimuth. Primera Edición. marcó, según a Quiceno Castrillón (1998, P. 59) ${ }^{15}$ la mayoría de los maestros, sus enseñanzas, su metodología, sus maneras de ver la vida, sus ideas de tiempo, de la formación, su relación con la ciencia, con las personas y con la subjetividad, derivado ello de las bases mismas sobre las cuales estaba sustentada la educación: como crianza, como instrucción y como formación.

Para los maestros, la educación como crianza de los seres humanos, implicaba asemejar a los niños con seres débiles e indefensos como las plantas que necesitaban siempre de protección y cuidados para educar, mediante el sometimiento y la servidumbre, esa autoridad fuerte que Dios creó, que la iglesia recogió y que los curas y maestros aplicaban mediante la autoridad fuerte, imponente, capaz de dirigir la conducta, el alma y ser de una persona.

De esa manera, los maestros concebían la formación como el resultado del sometimiento del sujeto al proceso de crianza e instrucción, pues ello lo conducía, intencionalmente, a moldear su forma de hablar, de conducir su vida, su lenguaje educativo, es decir, a llegar a la forma que se necesitaba, a la inventada y creada. Educar significaba ser criado, instruido y formado mediante las formas pedagógicas utilizadas para ello: las clases, las tareas, el aprender, la enseñanza y las lecciones. (Quiceno, P. 60).

Para el caso de Caldas, puede plantearse que el maestro estaba concebido, ya para finales de la década de 1960, como el intelectual pequeño burgués, encargado de elaborar y transmitir una visión científica e ideológica de la realidad que iba determinando de una vez la mentalidad del estudiante. En esa medida él era el encargado de impartir y transmitir conocimientos, pues estaba formado para enseñar lo que se debía enseñar; y el estudiante el que recibía, asimilaba, quien aprendía, aunque ignorara haberlo hecho, así fueran fundamentos ideológicos para un saber proletario. "Al maestro se le pide que se presente, no únicamente como un hombre que posee un saber, sino que además sea testigo de la verdad y el afirmador de los valores. El maestro en saber, enseña, además y a veces a pesar suyo, la insuficiencia de saber. Porque el saber auténtico, al profundizarse, aboca a un no-saber. El saber conduce a la toma de conciencia de los límites del saber, que precisamente son las condiciones de existencia del hombre. (Acevedo C., 1978:109-116)16

Ahora bien, un aspecto importante a tener en cuenta en la profesión docente es el origen social de las personas dedicadas a este oficio; ante esta situación, se hace necesario revisar los datos arrojados por un estudio realizado en la 
década de 1970 en la ciudad de Tunja, ${ }^{17}$ con maestros que asistían a un curso de capacitación y el cual puede decirse es el reflejo de la situación social de los padres de los maestros del país. En relación con la ocupación de los padres, el estudio evidencia que la mayoría de los maestros provenían de clases medias tradicionales, aquellas que trabajaban por cuenta propia y eran dueñas de sus instrumentos de labor: artesanos, pequeños negociantes y pequeños y medianos propietarios. De igual manera, según Acevedo (1978: 78), algo semejante se encuentra en las Escuelas Normales, pues la demanda provenía de la clase media baja de las pequeñas ciudades y pueblos (comerciantes, artesanos, funcionarios menores). Estos grupos, añade el estudio, se han percatado recientemente de las nuevas posibilidades de ascenso social mediante la educación secundaria y superior, y desean y están en condiciones de pagar los modestos honorarios.

En términos generales se encuentra que los maestros provienen de familias de estrato social medio que siguieron este oficio por ser una de las mejores opciones para vincularse rápidamente en el mundo laboral, y de otra parte, por que la mejor alternativa de estudio, especialmente en los pueblos, era la de realizar estudios en Escuelas Normales, las que por su carácter y objeto de formación les habilitaba para ejercer una profesión: Ser maestros.

\section{Obligación o vocación: El inicio de la profesión docente}

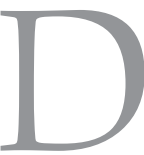

esde mediados del siglo XX se caracterizó la población egresada de las Escuelas Normales de Caldas por tratar, en lo posible, de dar continuidad a la formación impartida en esas instituciones y sucesivamente encauzarla en la vecindad donde eran nombrados; es decir, en las escuelas primarias urbanas y rurales y los colegios académicos o normalistas; sin embargo, algunos de ellos optaron por otras labores, quehaceres y empleos que significaban mayores retribuciones, dignidades y recompensas, económicas y personales.

"Ingresé a la Normal porque aquí no había otra alternativa, porque no había más que estudiar, era lo único que había: en la Normal entonces, tocaba estudiar, pero a mí no me gustaba ser maestra, la educación y el interés por lo pedagógico no fue innato sino adquirido". ${ }^{18}$

Ser maestro significó, en algunos casos, descubrir la aptitud por formación y experimentación, pues cierta parte de la población estudiantil, que ingresaba a las Escuelas Normales, negaba la posibilidad subsiguiente de desempeñarse
${ }^{17} \mathrm{El}$ objeto del estudio era recabar información sobre el origen social las condiciones de Comunidad. Tomado de: CASTAÑO Gonzalo. Educación y estructura social. Editorial Plaza \& Janés, Bogotá, 1989. Pp. 73- 74.

${ }^{18}$ Entrevista a la profesora Ester Marín Jiménez, (1959). Filadelfia, Caldas, (noviembre: 2004). 
${ }^{19}$ En diversos estudios, como el realizado por Gonzalo Castaño, en la década de 1980, dan cuenta, que una de las principales razones por las cuales se ingresaba al magisterio en Colombia estab refrendada por el nivel socioeconómic aspirantes, pues al no contar con la posibilidad de desplazarse a la ciudad a iniciar sus estudios universitarios, la mejor opción er buscar el ingreso a la docencia pare recibir docencia, para recibi un sueldo de maner más o menos rápida pues hasta la década de 1980 no tuvo mayores requisitos, salvo ser normalista, o esta dispuesto a desplazarse a una zona rural, estar presto a realizar cursos de capacitación en pedagogía.

${ }^{20}$ La convicción de ejercer la docencia, estaba amparada en el don carismático y amoroso carismático y amoroso demostrado por la mujer, aspecto que se consideraba esencial, para quienes se dedicaran a esta noble labor, es decir la vocación se respaldaba en el espírit maternal, más que en la misma preparación necesaria para ejerce esta profesión; de igual manera, en las Escuela Normales, a través de sus prácticas y los consejos de los maestros, fueron potenciando ese espíritu de formadoras, a partir del esfuerzo y la dedicación, con lo cual convencieron a sus estudiantes de tener dicha vocación.

${ }^{21}$ Entrevista a la profesora Soledad Velás quez García, (1958) quez García, (1958)
Anserma, Caldas, (noviembre: 2004). en el campo magisterial por considerar que esta profesión de ninguna manera estaba hecha para ellos; sin embargo, ante las pocas posibilidades para continuar con estudios de bachillerato, especialmente para las mujeres, cuyos padres querían que estudiaran en instituciones femeninas y no mixtas, por los prejuicios propios de la época.

Con el transcurrir del tiempo, con la experiencia adquirida, con la configuración intelectual, experimental, moral y ética descubrieron que tenían la disposición para ser maestros, para trabajar con la población en edad estudiantil, que tenían las capacidades para desempeñar una labor tan noble como el magisterio.

La decisión de formarse como educadores, tenía entonces dos posibilidades, una, era la de estudiar en las Escuelas Normales por obligación, ${ }^{19}$ por no existir otra opción, especialmente para las mujeres, y así, emplearse de manera más o menos rápida; y en segundo orden por convicción; ${ }^{20}$ es decir, aquellas personas que desde temprana edad descubrieron, como lo plantearon varios de los maestros, la vocación por la profesión y amor por la formación de los niños y jóvenes, estableciendo un gran compromiso con su región; sin embargo, es válido reconocer que en ambas situaciones, por obligación, incluyendo la necesidad, o por vocación, los maestros se adaptaron a su labor y la ejercieron con dedicación, aunque básicamente siguiendo el modelo pedagógico con el cual fueron formados.

La ocupación de maestro representó, para muchos, el incentivo más atractivo para acceder a la estabilidad económica esperada, tanto por los padres de familia, acreedores y afines, como por ellos mismos, pues la labor docente permitía al trabajar con un sueldo estable, retribuir en parte el esfuerzo hecho a quienes apoyaron su educación durante los años normalistas.

"Estudié en la Normal pues porque en ese tiempo era la institución que había, porque preparaba a las mujeres para luego ejercer la docencia, ser maestras, entonces qué mirábamos nosotros, una oportunidad de salir a trabajar primero porque nos gustaba la vocación, nos gustaba enseñar, nos gustaban los niños y también más tarde para poder ayudar a nuestros padres, el esfuerzo que ellos hacían en educarnos". ${ }^{21}$

En sus inicios fue revelador el porcentaje de graduados que comenzaron a laborar inmediatamente después de culminar sus estudios normalistas, 
desempeñándose en las instituciones para las cuales fueron preparados, generalmente circundantes a las cabeceras municipales de donde eran oriundos, en veredas alejadas o en caseríos vecinales, a veces de difícil acceso.

"Esos inicios fueron como bien trabajaditos porque uno iba como un chocolito allá a la escuela, sin nada más que la disposición, no sabía a que grupo me iba a enfrentar, no sabía sí en la escuela había o no había material; empezamos a trabajar y cada que necesitábamos de un material se programaba para la semana siguiente, como dormíamos en la escuela, veníamos cada ocho días (...)".22

En algunos territorios los recién egresados tuvieron que comenzar a trabajar desde cero, dado que el lugar a donde eran enviados carecía de condiciones aptas para desempeñarse; en esa medida, organizar la escuela les implicó adecuar locación, mantenimiento, elección de la población estudiantil, matrículas, libros reglamentarios, sostenimiento, material de enseñanza, preparación de clases para los diferentes grados y, cuando fuera necesario, apoyar el restaurante escolar y la huerta; en otras palabras allí aprendieron a utilizar todos los conocimientos adquiridos, tanto educativos, como pedagógicos y disciplinares.

"Uno al principio llega muy asustado con tanto niño pequeñito. Uno sale de la Escuela Normal y comienza a trabajar muy asustado, hasta que va cogiéndole el hilito y sobre todo por que salimos confiados, yo por ejemplo, inicié la docencia en la escuela Celmira Piedrahíta, esa queda acá en la zona urbana, trabajé varios años allí, fue muy duro porque nos tocó trabajar con grupos de 80 y 85 alumnos en un sólo salón, por tanto era necesario preparar bien las clases y por fortuna nos desenvolvíamos muy bien, para dar todas las materias, difícil pero lo hacíamos.

Muchos maestros fueron prácticamente los fundadores de las instituciones para las cuales eran enviados, pues para la época estaba vigente la política de ampliación de cobertura en educación, lo que promovió la construcción de escuelas en diversos sectores rurales; de otra parte, en Caldas, el Comité de Cafeteros se preocupó por apoyar el desarrollo educativo de estos sectores, patrocinando la construcción de edificaciones; sin embargo, era necesario dotarlas y este papel le fue conferido a los maestros, quienes se convirtieron en lideres gestores de recursos para tal fin.

${ }^{22}$ Entrevista a la profesora Miriam Franco, (1970). Filadelfia, Cal-
das, (noviembre: 2004). 
${ }^{23}$ Entrevista a las profesoras Berta Cecilia Giraldo y Carmenza Porras, (1969). Anserma, Caldas, (noviembre: 2004 ).

${ }^{24}$ Entrevista a la profesora María Graciela Díaz Marín, (1964) Pensilvania, Caldas (noviembre: 2004).
"La escuela había sido construida con el Comité de Cafeteros. Me tocó gestionar para recaudar fondos para la construcción del restaurante, para adquirir materiales aunque no como directora, ya luego me tocó gestionar para la construcción de otras aulas". ${ }^{23}$

Muchas actividades que inicialmente desarrollaron los recién graduados fueron enseñadas en la Escuela Normal a la cual concurrieron aunque, en algunas ocasiones, esas indicaciones fueron limitadas, pues a la hora de aplicarlas se quedaron incompletas frente a la responsabilidad tan grande que realmente tuvieron que enfrentar. Actividades realizadas por herencia cultural, como visitar el templo católico cada domingo, hacer una reflexión u oración al comenzar el día, fomentar valores patrios, religiosos y morales, entre otros; aspectos que refuerzan lo comentado anteriormente, frente a la injerencia y marcada formación religiosa que se tenía en las Escuelas Normales, aspecto que influyó también en los procesos pedagógicos de los maestros.

Tal vez una de las grandes dificultades en la preparación de los maestros, fue el hecho de haberlos intentado formar a imagen y semejanza de quienes les enseñaban; motivo que hizo que los enseñantes en formación se acostumbraran a realizar las actividades previamente planeadas con sus maestros de práctica y aprobadas por estos, en este sentido, no tuvieron autonomía a la hora de tomar decisiones sobre lo que debían enseñar y la forma en que debían y podían hacerlo. Todo estaba supeditado a la orientación de actividades autorizadas por sus superioras, asunto que ya no encontraban al momento de desempeñarse como docentes en propiedad y esta situación causaba, además de muchos temores, incredulidad en sus capacidades.

"Cuando me nombraron, llegué allá y como estaba acostumbrada a ser normalista, me gradué en noviembre y en febrero, me mandaron a trabajar con el grupo y me dieron la autonomía de hacer con el grupo lo que yo quisiera, icómo así? pues estaba enseñada a que me mandaran, que vea haga así, haga tal cosa, haga la otra, entonces eso fue como abra los ojos mijita que usted ya es maestra, fue muy complicado despertar ante ese reto". ${ }^{24}$

Ante la falta de experiencia pedagógica de los recién egresados, especialmente frente al tema de grupos con diversas dificultades sociales, los nuevos maestros recurrían siempre a la tutela de los más experimentados, al fin y al cabo estaban enseñados a estar controlados y aconsejados por sus maestros 
de la normal, en sus prácticas, y hasta no tener la trayectoria suficiente no se asumía la autonomía en la orientación de los cursos, aunque sí en la autoridad, aspecto bien trabajado desde las Escuelas Normales.

Otro asunto interesante para esta época, era la forma como eran citados los docentes, para ello, diversos procedimientos fueron los utilizados por la Secretaría de Educación Departamental a la hora de nombrar los jóvenes maestros normalistas, superiores o elementales; entre ellos las citaciones, los telegramas, los avisos por diferentes medios de comunicación como el periódico y la radiodifusora local o regional.

"Me gradué en la Normal Superior de la Presentación, Pensilvania, en ese entonces todo el personal, presentaba la solicitud de empleo ante la Secretaría de Educación o la Normal enviaba el listado de quienes se graduaban, uno se quedaba en la casa esperando el nombramiento; ese fue el primer año en que comenzaron a ubicar los maestros normalistas en la zona rural, porque mandaban a las veredas pero a los bachilleres". ${ }^{25}$

Se presentó en algunas ocasiones que las decisiones de nombramiento eran tomadas desde las mismas Escuelas Normales, principalmente las regentadas por comunidades religiosas, que tenían para la época una autoridad y poderío tal, que podían decidir para donde se nombrarían sus egresados (as), la plaza que más les convenía, la institución más adecuada según su desempeño cuando fue estudiante y alumno-maestro, o si era merecedor de pertenecer a una Escuela Normal.

En términos generales, podría decirse que los normalistas tenían prelación para ser nombrados; sin embargo, los políticos de turno usaban la posibilidad de generar empleo en el magisterio, especialmente en los sectores rurales, en donde en virtud de las dificultades, se autorizaba, por vía de excepción, nombrar personal que no tuviera formación normalista, aunque si debía demostrar ser por lo menos bachiller, y eran precisamente estos quienes eran enviados a dichos sectores, por tanto se convirtieron en un fortín, quienes al no tener otra opción de trabajo, asumían la docencia como una posibilidad, a veces temporal y en otras permanente; es decir, en esta época, fruto del aprovechamiento politiquero de la educación, la formación como esencia de la educación y la pedagogía, no tenía la más mínima importancia, pues lo que se requería era demostrar que se estaban contratando los maestros que necesitaban las instituciones, y para ello bastaba tener algunos conocimientos
${ }^{25}$ Entrevista a la profesora Melva García Espinosa, (1969). Pensilvania, Caldas, (noviembre: 2004) 
${ }^{26}$ Quiceno, H. (1998) Breve recorrido histórico sobre el saber pedagógico. En: Revista Educación y Pedagogía No 19 y 20. Medellín: Universidad de Antioquia.

${ }^{27}$ Entrevista a la profesora Miriam Franco, (1970). Filadelfia, Caldas, (noviembre: 2004) que pudieran ser impartidos en las escuelas, ya lo pedagógico luego sería adquirido, mientras tanto deberían defenderse, son el ejemplo que habían tenido en las escuelas y colegios en los que se había estudiado.

En este sentido, cómo lo afirmara Quiceno (1998)²6: "La pedagogía nació separada de la educación como si fuera otra cosa". Es decir, pareciera que las instituciones escolares no necesitarán de ella para desempeñar mejor su labor, y por lo tanto lo importante era cumplir con los mínimos requisitos de una institución, tener quien diera las clases, sin importar su preparación y formación pedagógica; bastaba con tener algo que transmitir.

Una de las estrategias de la época para que los políticos pudiesen mantener cautivo su potencial electoral, fue la promesa de vinculación laboral a través del magisterio o la posibilidad de conseguirle a los egresados de las Escuelas Normales que sus nombramientos fueran en una institución urbana cercana a su lugar de residencia. Se acudía entonces a los políticos más destacados en los diferentes municipios del departamento, para que dieran apoyo a las solicitudes de nombramiento de los normalistas, de tal suerte que se agilizara dicho proceso y que además se garantizara el nombramiento en lugares cercanos.

A partir del reconocimiento de las posibilidades existentes de empleo en las décadas del 60 y 70 del siglo XX, y examinando que la mayor posibilidad de emplearse era la del magisterio, para lo cual no siempre fue necesario ser maestro normalista, ni demostrar formación pedagógica, ya que se dependía más de las necesidades de contratación que de la formación de los futuros enseñantes, lo cual fue muy bien aprovechado por los políticos para conseguir su potencial electoral.

"La profesión fue porque no había otra cosa, aquí el único empleo era el magisterio, todo el mundo quería ser maestro porque no había más que hacer y todo el que se graduaba era maestro, en ese entonces era facilísimo para cualquier persona, así no tuviera cartón, ni un grado, bastaba un buen apoyo político". ${ }^{27}$

Reconocer la intrusión de la política, no es nada nuevo, como tampoco lo es el reconocimiento de la forma como el manejo dado a los nombramiento afectó la calidad de la educación; en este sentido, con la intención de disminuir los efectos nocivos, al contratar personal no formado para ejercer la docencia, 
las mismas Escuelas Normales ofrecían cursos de capacitación en pedagogía, en los que se incluía la posibilidad de validación de la normal, en los períodos de vacaciones. ${ }^{28}$

A pesar de existir ya en esa época una alta injerencia de la política en el sistema educativo, es necesario reconocer que existía prioridad en los nombramientos para los normalistas, para quienes bastaba llenar las solicitudes, o tener el respaldo de sus instituciones o de los inspectores; en consecuencia, los egresados de las normales tenían casi asegurado su nombramiento, pues las políticas de expansión de educación en el país en ese tiempo, aumentaban las posibilidades ante la demanda educativa.

"En ese tiempo ofrecían los nombramientos muy fácil, de la Normal de Aguadas llevaban a la Secretaría la lista de los que se habían graduado y existía el Inspector de Núcleo, los Inspectores de Educación, el Inspector Local, ese inspector le preguntaba a uno para donde se quería ir y lo mandaban, sin intervención política, sin influencia". ${ }^{29}$

En ocasiones, cuando se alargaba el tiempo de nombramiento, se veían tentados los recién egresados a vincularse en actividades propias del municipio, como las secretarías de la alcaldía, del despacho parroquial o ser tenderos, vendedores, comerciantes, almacenistas, entre otros, que en absoluto tenían que ver con la profesión para la cual se prepararon; no obstante un porcentaje de estos rechazaron su profesión por haber ingresado a ella obligados por las circunstancias económicas o familiares, y al presentárseles una oportunidad laboral diferente, pero prometedora, la aceptaban indiscutiblemente.

"Cuando me gradué no comencé a trabajar ahí mismo como maestra porque a mí me llegó el nombramiento pero rural y yo no quería irme a una vereda; entonces tuve la oportunidad de trabajar en una empresa, Empocaldas, empresa recaudadora, allá a los trabajadores nos comenzaron a subsidiar el 80\% para hacer una carrera, yo elegí pedagogía porque, además de tener una base formativa como maestra en la Normal, la fundación Universitaria Luis Amigó, abrió un programa aquí, me gradué y al poco tiempo logré vincularme como maestra". ${ }^{30}$

Finalmente, se puede plantear que, independiente de las causas por las cuales se hubiese llegado al magisterio, era necesario que todo maestro comprendiera la necesidad de estar en consonancia con las exigencias del
${ }^{28}$ El Decreto No 180 de 1971 , institucionalizó la obtención del diploma de maestro, mediante exámenes dé validación de cursos completos en las Escuelas Normales, designadas para tal fin o con la presentación de un solo examen, que era polo examen, que era practicado pOr eTICFES Lo anterior se ratificó con el Decreto $N^{\circ} 124$ de 1973 que planteó en su literal g) ...sin embargo, el Departamento de común acuerdo con el Delegado del Ministerio podrá establecer terio podrá establece excepciones, con lo que se permitió incorporar maestros sin las calidades requeridas, pues les era permitido profesionalizarse luego. Esta situación desmotivó a los estudiantes de vó a los estudiantes as Escuelas Normales, pues ellos debían cursar un elevado número de asignaturas pedagógicas incluidas las prácticas docentes, con lo cual se veían en desventaja. MEN. Proyecto col 76/003. Op. cit. P. 211.

${ }^{29}$ Entrevista a la profesora Amparo González (1973). Aguadas, Caldas, (noviembre: 2004).

${ }^{30}$ Entrevista a la profesora Diva Nelly, maestra bachiller (1978). Neira, Caldas, (noviembre: 2004). 
oficio, por su carácter de formador y modelo a seguir; razón por la que era fundamental cumplir con unos principios éticos, propios de la profesión, so pena de ser sometidos al escarnio público y al detrimento de su imagen. Como refuerzo al comportamiento de los docentes, se divulgó ampliamente en las Escuelas Normales de Caldas, para la década de 1970, por parte de la Secretaría de Educación Departamental, el Código de Ética Profesional del Magisterio y además se hicieron ingentes esfuerzos para capacitar en formación pedagógica y así tratar de subsanar los errores en la contratación de personas sin idoneidad pedagógica para esta profesión.

\section{Metodología}

l proceso metodológico llevado a cabo para lograr dar respuesta al 1 interrogante central de la investigación, se enmarca dentro del campo de la Historia Social, pues el interés fundamental es, caracterizar y comprender los inicios y roles del maestro de las Escuelas Normales, con relación a su misión en las Instituciones Formadoras de Educadores por excelencia, y el compromiso establecido con la comunidad y con la región, entre 1963 y 1978, época en donde las reformas y tendencias educativas incidieron en la vida y trabajo de los maestros de aquel período.

Un asunto relevante en este proceso es que se confrontó la coexistencia y la combinación del testimonio y sus apreciaciones (lo subjetivo) que dan cuenta de las pretensiones de los actores, con los documentos, las memorias, los escritos, los informes, las actas, las evaluaciones, la legislación, etc. (lo objetivo), puesto que a través de esta combinación, se confrontaron los acontecimientos y la intenciones. Con base en lo anterior, fue necesario e imprescindible comprender a los maestros, tanto como sujetos que actuaban o tenían unos comportamientos colectivos y como individuos que interactuaban con su medio y su contexto $y$, que por tanto, tenían distintas formas de ver, entender y comportarse frente a su oficio y los lineamientos que condicionaron su desempeño.

La metodología utilizada en esta investigación, se sistematizó entonces, a partir de las siguientes etapas:

Una primera etapa reconocida como la heurística, referida a la búsqueda interrogada de las fuentes así como la determinación, localización, recolección, identificación y selección de las mismas. También se hizo la selección de fuentes orales: reconocimiento de los maestros y estudiantes que 
participaron en las entrevistas e historias de vida. En una segunda etapa, la doxografía, se realiza la ordenación, análisis, clasificación y sistematización de las fuentes y documentos básicos, como las historias orales, los currículos, los reglamentos, producción de los maestros, disposiciones, leyes, decretos, informes, memorias del período de estudio.

La tercera etapa hace referencia a la etiología, permitió establecer la claridad temática sobre los diferentes aspectos, hechos y realizaciones de los maestros de las Escuelas Normales del departamento de Caldas, como sujetos responsables de la formación de enseñantes. Finalmente, fruto de la cual se presenta el informe final, esta es la etapa de la síntesis histórica, en la cual los elementos extractados de las fuentes fueron correlacionados e integrados para construir un nuevo sentido a partir de la síntesis; desde esta perspectiva, una vez seleccionado, revisado y analizado todos los elementos se interpretan e interrelacionan para construir un nuevo sentido a partir del reconocimiento de la síntesis histórica, que permite la redacción del informe final. En esta etapa se determinaron los temas de manera definitiva; se fijaron las tendencias y se analizó la validez o no de las hipótesis, lo que permitió finalmente convertirlas en tesis para obtener las conclusiones.

\section{Conclusiones y nuevas aperturas}

os procesos de formación de maestros en Colombia y en el departamento
de Caldas corresponden a la convergencia de elementos políticos, religiosos
y económicos, por lo cual el proceso de formar educadores tuvo un fuerte talante político, del cual docentes en ejercicio y en formación hacen parte con o sin conciencia sobre ello y que hacen de la labor de educar al fututo educador un reto por un proyecto de país impuesto o transformado. La formación del maestro en el período de estudio refleja una mentalidad persistentemente religiosa y confesional, con la aspiración de educar y no solamente instruir; formar hábitos dignos antes que enseñar nociones teóricas; y tener siempre presente noble tarea de formar las inteligencias y los corazones. Se pretendía entregar personas dignas, laboriosas, patriotas y sobre todo, católicas.

La decisión de iniciarse en la formación como educadores, en las Escuelas Normales, era básicamente por dos alternativas: una estudiar en estas instituciones por obligación, por no existir otra opción de estudio, especialmente para las mujeres, así como por la posibilidad de poder emplearse de manera más o menos rápido; y de otra parte, por convicción: aquellas personas con profunda vocación por la profesión y amor por la formación 
de los niños y jóvenes. En todo caso es necesario aceptar que en ambas situaciones, por obligación o por convicción; los maestros se adaptaron a su labor y la ejercieron con responsabilidad a partir del modelo con el cual fueron formados.

Los procesos de enseñanza en las décadas de 1960 y 1970, se especializaron en un modelo pasivo donde el maestro conferenciaba tratando de difundir los conocimiento necesario para la formación de los educandos, según los presupuestos del Ministerio de Educación Nacional; sin embargo, en muchos casos se convirtieron en conocimientos carentes de interés para el alumnado; era una enseñanza academicista, transmisionista, basada en textos y guías propuestos desde el Ministerio de Educación, donde el único trabajo activo del educando era repetir sobre el cuaderno la lección, responder después; desde esta perspectiva, la enseñanza se basaba más en la memoria que en la inteligencia. Lo esencial era la repetición y la modelación.

Los maestros y profesores se caracterizaron por tener la obligación de transmitir valores patrimoniales, religiosos y éticos con la intención de instruir sobre las maneras convenientes de actuar, hablar y comportarse; pero siempre fue necesario mantener la distancia con sus alumnos, al considerar que una excesiva confianza perturbaría el dominio sobre ellos; sin embargo, trataron de entablar relaciones humanas amenas dentro de un ambiente educativo favorable para la enseñanza.

Como principal conclusión del presente artículo, podría decirse que el maestro de las Escuelas Normales en el Departamento de Caldas entre 1963 y 1978 correspondió a un sujeto socio-político que se movió entre las tendencias educativas que llegaron a innovar las prácticas de enseñanza y formación, con el rol social establecido tradicionalmente de ser forjadores de principios y valores que dieran ejemplo no solo de ciudadanos, sino de cristianos. Por tanto, los maestros no se movilizaron únicamente alrededor de las directrices nacionales, sino del imaginario otorgado por las comunidades al maestro en el sentido formativo e incluso ideológico. En todo esto también prima la docencia como un oficio, en el cual el ingreso va más allá de la comprensión real del ejercicio de enseñar y formar niños y jóvenes, sino de una necesidad de ingreso al mercado laboral, principalmente para las mujeres.

Los desafíos de estos maestros fueron geográficos, sociales y académicos; pues la formación o el ingreso no mostraron las realidades a las cuales se 
enfrentaron y que son quizá la fortaleza más representativa del discurso pedagógico de los maestros caldenses en el período de estudio, principalmente en la experiencia de laborar en las zonas rurales donde las guías, el material, la infraestructura y el mismo entorno debían ir más allá del enseñar contenidos a niños de primaria.

Todo esto hace comprender el por qué y el cómo llegan las personas a ser maestros, es algo que va más allá de la vocación docente, lo cual no lo convierte en un obstáculo o crítica, sino en una posibilidad para nuevos y diferentes estudios en Historia de la Educación, bajo la comprensión de que la docencia y la escuela no son escenarios fuera de las construcciones sociales y políticas del país, las regiones y las localidades.

\section{BIBLIOGRAFÍA}

Acevedo, J. (1978). Educación y contratación. Contribución al análisis del problema de la contratación en la educación. Universidad de Antioquia, Facultad de Educación. Medellín: Azimuth. Primera Edición.

Alzate, G. (1957). Grandes oradores colombianos. Colección Banco de la República. Colombia.

Abarca, R. (1996). Vocabulario filosófico científico. Universidad Católica de Santa María. Arequipa. Recuperado de: http://www.ucsm.edu.pe/rabarcaf/voficio6.htm

Báez, M. (2004). Las Escuelas normales y el cambio educativo en los Estados Unidos de Colombia en el Período Radical, 1870-1886. Tunja, Boyacá: UPTC.

Bohórquez, L. (1957). La evolución educativa en Colombia. Bogotá: Publicaciones cultura colombiana, LTDA.

Burdín, J. (1975). El mundo cambiante y sus implicaciones para la educación de los maestros;

Cogan, M. Problemas actuales de la educación de profesores. Seminario sobre formación de docentes para el sistema educativo. Bogotá.

Cruz, M. (1977). La crisis del stalinismo: el caso Althusser. Barcelona: Editorial Península.

De Tezanos, A. (1984). La efectividad del maestro. Estudio Etnográfico sobre sus Orígenes en la Escuela Normal. Informe Preliminar, Bogotá: CIUP.

Duque, I. (1972). Problemática educativa colombiana. Bogotá: Biblioteca del Educador. Editorial Voluntad.

Díaz, M. (1989). La reforma curricular. En: Revista Educación y Cultura, No. 4. 
Díaz, M. (1989). Sobre el discurso instruccional. En: Revista Colombiana de Educación, No. 17.

Díaz, M. \& Chávez, C. (1990). Las reformas de la escuelas normales, un área en conflicto. En: Revista Educación y Cultura, No. 20.

De Montaigne, M. (1948). Ensayos. Buenos Aires: El Ateneo, tomo I.

De Montaigne, M. (1962). Ensayos pedagógicos. Madrid: La Lectura.

Fandiño, G. (1984). Tendencias actuales en la educación. Bogotá: Universidad Santo Tomas: Centro de Enseñanza Desescolarizada.

Gantiva, J. (1985). Agustín Nieto caballero y la Escuela Nueva. En: Revista Educación y Cultura, No 3, marzo, Bogotá.

Gómez, H. (1985). Diccionario de la historia de Colombia. Bogotá: Circulo de Lectores. Plaza y Janés, Editores Colombia.

González. G \& Fernán (1978). Educación y Estado en la historia de Colombia. La educación bajo los regímenes conservadores: Restauración ideológica. Editorial Controversia. Bogotá: CINEP.

González, S. J. \& Fernán, E. (2002). La Iglesia en el Siglo XX. Las reformas al Concordato. En: Revista Credencial Historia. Bogotá, Colombia. Edición 153.

Loaiza, Y. (2009). Sabio o erudito: el maestro de las escuelas normales 1963-1978. Universidad de Caldas. Facultad de Artes y Humanidades, Manizales.

MEN- Oficina Sectorial de Planeación Educativa. (1986). La planeación educativa en Colombia. 1950-1986. República de Colombia. Programa de Planeación Educativa Regional. PLANER. Bogotá.

Melo, J. (1996). Colombia hoy. Biblioteca virtual del Banco de la República. Luis Ángel Arango. Recuperado de: http://www.banrep.gov.co/blaavirtual/letra-c/colhoy/colo6.htm

Parra, R. y otros (1982). La profesión del maestro y el desarrollo en Colombia. Ensayo publicado en: Revista Proyecciones Educativas, MEN, Bogotá.

Parra, R. (1986). La escuela inconclusa. Plaza y Janes Editores, Bogotá.

Parnett, J. (1986). La imagen del maestro en la historia. En: Revista Educación y Cultura, Número 8, Bogotá.

Quiceno, H. (1998) Breve recorrido histórico sobre el saber pedagógico. En: Revista Educación y Pedagogía No 19 Y 20. Medellín: U de A.

Restrepo, B. ( $\sin$ año de publicación). Formación y capacitación del magisterio. Biblioteca del Educador: Ediciones Voluntad, Bogota. 
Rodríguez, J. (1961). Manual de pedagogía de los años sesentas. Medellín: Bedout.

Socarrás, J. (1979). Facultades de educación y escuela normal superior. UPTC, Tunja.

Sánchez, R. (1984). Estado y planeación en Colombia. Capítulo III. Editorial La Rosa Roja. Colombia. Bogotá.

Tirado, A. (1989). Nueva historia de Colombia. N.H.C. Tomo II. Historia política 1946-1966. Capítulo 14. Bogotá: Editorial Planeta.

Valencia, C. (2006). Las escuelas normales y la formación del magisterio, primera mitad del siglo $X X$. Rudecolombia. 